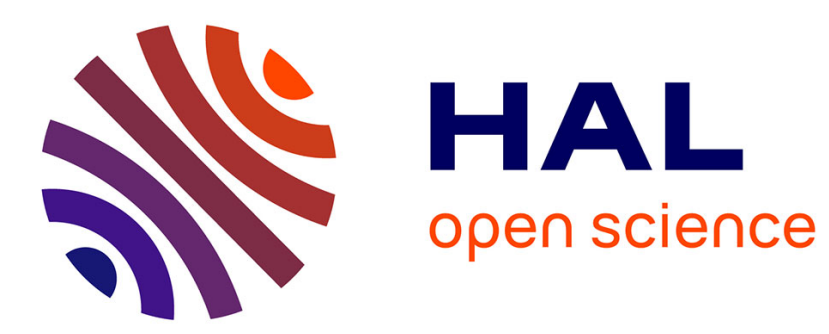

\title{
Mapping short-wave albedo of agricultural surfaces using airborne PolDER data
}

Frédéric Jacob, Albert Olioso, M. Weiss, Frédéric Baret, O. Hautecoeur

\section{To cite this version:}

Frédéric Jacob, Albert Olioso, M. Weiss, Frédéric Baret, O. Hautecoeur. Mapping short-wave albedo of agricultural surfaces using airborne PolDER data. Remote Sensing of Environment, 2002, 80 (1), pp.36-46. 10.1016/S0034-4257(01)00265-6 . hal-02679255

\section{HAL Id: hal-02679255 \\ https://hal.inrae.fr/hal-02679255}

Submitted on 3 Nov 2021

HAL is a multi-disciplinary open access archive for the deposit and dissemination of scientific research documents, whether they are published or not. The documents may come from teaching and research institutions in France or abroad, or from public or private research centers.
L'archive ouverte pluridisciplinaire HAL, est destinée au dépôt et à la diffusion de documents scientifiques de niveau recherche, publiés ou non, émanant des établissements d'enseignement et de recherche français ou étrangers, des laboratoires publics ou privés. 


\title{
Mapping short-wave albedo of agricultural surfaces using airborne PolDER data
}

\author{
F. Jacob ${ }^{* \dagger}$, A. Olioso, M. Weiss, \\ F. Baret, O. Hautecoeur ${ }^{\ddagger}$
}

17th December 2001

\footnotetext{
${ }^{*}$ INRA Climat-Sol-Environnement, Avignon, France

${ }^{\dagger}$ USDA/ARS Hydrology and Remote Sensing Laboratory, Beltsville, MD, USA

${ }^{\ddagger}$ CESBio CNES/CNRS/UPS, Toulouse, France
} 


\begin{abstract}
This study focuses on albedo mapping over agricultural surfaces using multi-directional and multi-spectral remote sensing data. These data were acquired using the airborne PolDER sensor during the ReSeDA experiment. The data set allowed to perform a validation over the growth cycles of several crops. Problems induced by mixed pixels were reduced since the ground spatial resolution was $20 \mathrm{~m}$. First, linear kernel-driven BRDF models were used to retrieve the whole BRDF and then to compute the hemispherical reflectance in the PolDER channels. We tested the four most classical models: Li-Ross, MRPV, Roujean and Walthall. They presented similar interpolation performances, whereas the quality of the hemispherical reflectance estimates was also driven by the extrapolation performances. Second, the albedo was computed as a linear combination of the wave-band hemispherical reflectances. We used several sets of coefficients proposed in the literature for different sensors. The validation of the albedo maps against field measurements showed that it was possible to achieve a relative accuracy about $9 \%$ when using an appropriate coefficient set.
\end{abstract}




\section{Introduction}

Surface albedo is defined as the fraction of incident solar energy (diffuse and direct components) reflected both in all directions above the surface and over the whole solar spectrum (Pinty \& Verstraete, 1992). Its knowledge is of prime interest for weather forecast and climate modeling (Dickinson, 1992), as well as for surface

flux estimation (Kustas et al., 1994; Olioso et al., 1999). The required accuracy varies from an application to another. Sellers (1993) cited an absolute accuracy about $\pm 2 \%$. Visible - Near Infra-Red remote sensing is an interesting tool for monitoring albedo since it can frequently provide maps at local and regional scales. However, remotely sensed data sample the bidirectional reflectance in a limited number of viewing directions and over a limited number of wave-bands. Therefore, the albedo estimation from such data requires first, to characterize the whole angular distribution of the bidirectional reflectance from the sensor directional sampling (Walthall et al., 2000); and second, to perform a spectral extrapolation from observations in few wave-bands, so called the narrow-band to broad-band conversion (Song \& Gao, 1999).

The retrieval of the whole BRDF (Bidirectional Reflectance Distribution Function) from the angular sampling provided by a multi-directional data set can be performed by the inversion of either a radiative transfer model or a kernel-driven BRDF model. The inversion of a radiative transfer model is time consuming since it requires tedious numerical procedures. It is also mathematically complex be- 
cause of problems such as the choice of initial guess of the parameters to be deduced, the choice of the merit function, the local minima, or the variable ambiguities (Pragnère et al., 1999). On the other hand, kernel-driven models are not costly to compute since only few parameters have to be tuned (Lucht \& Roujean, 2000). Besides, the use of linear kernel-driven models both eases the procedure of inversion that becomes analytical and provides estimates independent of the spatial resolution (Brown de Colstoun et al., 1996). Of course, non linear models that can be linearized have almost the same interesting properties. In this context, several studies suggested the operational implementation of linear kernel-driven BRDF models for albedo mapping at the global scale (Roujean et al., 1992; Baret et al., 1997; Wanner et al., 1997; Lucht et al., 2000).

The narrow-band to broad-band conversion can be performed by expressing the albedo as a linear combination of bidirectional or hemispherical reflectances in a selection of wave-bands. Such a linear method presents also the interest not to depend on the spatial scale. The determination of the coefficients has been investigated by several authors, mainly using the red and near infrared channels of the NOAA/AVHRR sensors. Several empirical sets of coefficients were proposed, and Song \& Gao (1999) suggested to express them as empirical functions of the NDVI. Other recent works were devoted to new sensors, considering either bidirectional reflectance (Liang et al., 1999) or hemispherical reflectance (Weiss et al., 2001).

The objective of this study was to map instantaneous surface albedo using 
multi-directional and multi-spectral remote sensing data. It was based on the ReSeDA (Remote Sensing Data Assimilation) experiment (Prévot et al., 1998; Olioso et al., 2001) that provided an interesting framework for assessing the methods discussed above. During this experiment, Visible - Near Infra-Red remote sensing data were acquired over agricultural surfaces using the airborne PolDER imaging radiometer (Leroy et al., 2001). These high spatial resolution data were multitemporal, allowing to perform a validation over the growth cycles of several crops while problems due to mixed pixels were reduced. Several linear kernel-driven BRDF models and several sets of coefficients for the narrow-band to broad-band conversion were evaluated to compute maps of albedo. Finally, these maps were validated against field measurements.

\section{Data acquisition and preprocessing}

The ReSeDA site was located close to Avignon (France), north of the Alpilles small mountain chain ( $\mathrm{N} 43^{\circ} 47^{\prime}$ latitude, $\mathrm{E} 4^{\mathrm{O}} 45^{\prime}$ ' longitude). It was an approximately $5 \times 5 \mathrm{~km}^{2}$ size agricultural region, with sunflower, wheat, corn, grassland and alfalfa fields about $200 \times 200 \mathrm{~m}^{2}$ size (Figure 1). During the experiment that lasted from December 1996 up to December 1997, PolDER data were collected approximately every three weeks, and field measurements of albedo were performed daily. We propose here an overview of the data acquisition and preprocessing. More detailed descriptions are given by Leroy et al. (2001); Olioso et al. (2001); François 
et al. (2001).

[Figure 1 about here.]

\section{Remote sensing data}

The PolDER sensor (Deschamps et al., 1994) flew during 16 clear sky days from January, 30th to September, 18th. Nominal flight altitude was about 3000 m, which yielded a 20 m nadir spatial resolution. Four flight lines were parallel to the principal plane and one was perpendicular. The five lines were completed within 45 minutes centered around solar noon. PolDER measurements were performed in four $40 \mathrm{~nm}$ width wave-bands centered at $443 \mathrm{~nm}, 550 \mathrm{~nm}, 670 \mathrm{~nm}$ and $865 \mathrm{~nm}$. They corresponded to zenith view angles ranging from 0 to $50^{\circ}$. The instrument was calibrated by the Laboratoire d'Optique Atmosphérique (Lille, France) approximately every three weeks during the experiment. The calibration had a 5\% accuracy, and showed a temporal drift of the sensor response over the twelve months of the experiment. Atmospheric effects were corrected using the SMAC code (Rahman \& Dedieu, 1994). The input variables were field measurements or climatological data of integrated atmospheric water vapor content, aerosol optical thickness at $550 \mathrm{~nm}$ and ozone concentration. No accuracy was proposed for these atmospheric corrections. Image registration was performed thanks to the data provided by an electronic subsystem aboard the plane including a Global Positioning System and a gyroscopic central unit. The images were geometrically matched according to a Lambert II projection that provided a $20 \mathrm{~m}$ spatial sampling of the experimental 
site.

\section{Field data}

In-situ albedo was estimated as ratio of reflected to incident solar radiation measurements. Reflected radiation was measured with Kipp pyranometers or Skye silicon sensors located on seven fields that corresponded to alfalfa, sunflower and wheat crops. The footprints ranged from 1000 to $3000 \mathrm{~m}^{2}$. Incident radiation was measured on the meteorological station located on the center of the experimental site, using a Kipp pyranometer. The Kipp sensors were calibrated to provide estimates of incoming radiation over the whole solar spectrum from measurements over the 400 - $3000 \mathrm{~nm}$ spectral band. The Skye sensors measured incoming radiation between 400 and $1100 \mathrm{~nm}$. It was necessary to consider the spectral behavior of the observed surfaces to extrapolate the SKYE measurements over the whole solar spectrum. A correction procedure has been developed by François et al. (2001). The SAIL model (Verhoef, 1984) was supplied with both spectra of incident solar radiation and in-situ data characterizing soil and vegetation to simulate Kipp and Skye albedos. Incident solar radiation spectrum was computed from simulations using the $6 \mathrm{~S}$ atmospheric radiative transfer code (Vermote et al., 1997). The simulations accounted for numerous atmospheric situations. The soil and vegetation characteristics were leaf and soil reflectance spectra, and Leaf Area Index. Based on these simulations done by François et al. (2001), we calibrated a linear regression between actual (i.e. Kipp) and Skye albedos at solar noon. The linear 
regression provided a residual error of Root Mean Square Error $=0.003$ :

$$
\text { Albedo }_{\text {actual }}=0.785 \times \text { Albedo }_{\text {Skye }}+0.02
$$

\section{Retrieving albedo from multi-directional and multi-spectral data}

\section{From measurements to variables of interest}

From the definition given in introduction, surface albedo $a\left(\theta_{s}, \varphi_{s}\right)$ can be expressed as:

$$
a\left(\theta_{s}, \varphi_{s}\right)=\frac{\int_{300 n m}^{3000 n m} \rho_{h, \lambda}\left(\theta_{s}, \varphi_{s}\right) R_{g, \lambda}\left(\theta_{s}, \varphi_{s}\right) d \lambda}{\int_{300 n m}^{3000 n m} R_{g, \lambda}\left(\theta_{s}, \varphi_{s}\right) d \lambda}
$$

where the hemispherical reflectance $\rho_{h, \lambda}\left(\theta_{s}, \varphi_{s}\right)$ represents the fraction of incident solar radiation $R_{g, \lambda}\left(\theta_{s}, \varphi_{s}\right)$ reflected in the whole hemisphere for a given wavelength $\lambda$ and given solar zenith and azimuth angles $\left(\theta_{s}, \varphi_{s}\right)$. It can be formulated through the bidirectional reflectance $\rho_{\lambda}\left(\theta_{s}, \varphi_{s}, \theta_{v}, \varphi_{v}\right)$ :

$$
\rho_{h, \lambda}\left(\theta_{s}, \varphi_{s}\right)=\int_{0}^{2 \pi} \int_{0}^{\pi / 2} \rho_{\lambda}\left(\theta_{s}, \varphi_{s}, \theta_{v}, \varphi_{v}\right) \cos \theta_{v} \sin \theta_{v} d \theta_{v} d \varphi_{v}
$$

where $\theta_{v}$ and $\varphi_{v}$ are respectively zenith and azimuth view angles.

Equation 3 shows that estimating the hemispherical reflectance requires knowledge of the whole BRDF. Moreover, equation 2 underlines the necessity to know the hemispherical reflectance over the whole solar spectrum. On the other hand, the PolDER sensor provided measurements of the bidirectional reflectance $\rho_{\lambda_{j}}\left(\theta_{s}, \varphi_{s}, \theta_{v}, \varphi_{v}\right)$ for a selection of viewing directions $\left(\theta_{v}, \varphi_{v}\right)$ and over the four wave-bands $j$. Therefore, from this directional and spectral sampling, we first 
computed the wave-band hemispherical reflectances $\rho_{h, \lambda_{j}}\left(\theta_{s}, \varphi_{s}\right)$ by inverting linear kernel-driven BRDF models, and second the albedo as a linear combination of these hemispherical reflectance estimates.

\section{Hemispherical reflectance estimation using linear kernel-driven BRDF models}

A linear kernel-driven BRDF model expresses the bidirectional reflectance as a superposition of several basic BRDF shapes, i.e. a linear combination of $n$ kernels $K_{i}\left(\theta_{s}, \varphi_{s}, \theta_{v}, \varphi_{v}\right)$ that only depend on illuminating and viewing conditions:

$$
\rho_{\lambda}\left(\theta_{s}, \varphi_{s}, \theta_{v}, \varphi_{v}\right)=\sum_{i=1}^{i=n} \alpha_{i, \lambda} K_{i}\left(\theta_{s}, \varphi_{s}, \theta_{v}, \varphi_{v}\right)
$$

where $\alpha_{i, \lambda}$ are the weighting coefficients that depend on both the wavelength and the nature of the pixel, and sometime on the sun position. The number of kernels and their formulations differ from a model to another with respect to the description of the radiative transfer for land surfaces. They can be purely empirical (Walthall et al., 1985), or semi-empirical since they derive from approximations of more detailed physical models (Roujean et al., 1992). Then, a multi-directional data set over a given wave-band $j$ allows to estimate rapidly and unambiguously the coefficients $\alpha_{i, \lambda_{j}}$ by solving the linear system $\left[\rho_{\lambda_{j}}\right]=[K]\left[\alpha_{\lambda_{j}}\right]$ thanks to a least square procedure (matrix pseudo inversion). Finally, the hemispherical reflectance is computed from the integration of the retrieved BRDF. This integration either analytically leads to a linear combinations of the coefficients $\alpha_{\lambda_{j}}$ or requires a numerical procedure that can be performed over a $24 \times 24$ direction Gaussian quadrature 
(Weiss et al., 1999). Among the several linear kernel-driven BRDF models that were developed these two last decades, the four most classical ones were chosen: Li-Ross (Wanner et al., 1995), MRPV (Engelsen et al., 1996), Roujean (Roujean et al., 1992) and Walthall (Walthall et al., 1985). We should notice that these models have three kernels, hence three coefficients $\alpha_{i, \lambda}$. The main phenomenological differences between them are: 1) the description or not of the hot spot effect, and 2) the reciprocal nature of the model (the viewing and illuminating directions can be inverted) that allows the description of the BRDF variation with respect to the sun position and further the retrieval of the diurnal course of albedo. Since the objective of this study was to map instantaneous albedo, we could use either reciprocal models or not.

Walthall is an empirical model that is not reciprocal and does not account for the hot spot effect. An improved variant that verifies the reciprocity principle was proposed by Nilson \& Kuusk (1989). However, Lucht (1998) showed that this improved version provides the worst BRDF and hemispherical reflectance retrievals as compared to other models. On the other hand, the original version presents good performances for both BRDF viewing angle interpolation and extrapolation (Baret et al., 1997), whereas it is one of the most robust models for studies at global scale including numerous land use situations (Strahler et al., 1996). Therefore, we chose the original version of Walthall. Li-Ross and Roujean are semi-empirical reciprocal models that do not account for the hot-spot effect. The three kernels 
are associated to particular physical processes (Wanner et al., 1995). Among the four versions proposed for the Li-Ross model to better account for different surface properties (Wanner et al., 1995), we chose the Li-Sparse / Ross-Thick variant. Indeed, this version was proposed by Wanner et al. (1997) for both plowed fields and vegetative surfaces, and was presented by Privette et al. (1997) and Lucht (1998) as one of the most accurate models. The Roujean model was tested over several measured and simulated data sets, and was often presented as a robust model with interesting performances (Roujean et al., 1992; Baret et al., 1997; Roujean et al., 1997; Privette et al., 1997; Chopping, 2000). MRPV is a semi-empirical reciprocal model that accounts for the hot spot effect. It describes the BRDF as the product of three functions. We used the semi-linearized version (Engelsen et al., 1996) that was validated over a range of land cover situations (Baret et al., 1997; Lucht, 1998; Weiss et al., 1999); and was presented as one of the best models for both interpolation and extrapolation of the sampled BRDF (Privette et al., 1997; Weiss et al., 2001).

\section{From wave-bands hemispherical reflectances to albedo: the narrow- band to broad-band conversion}

To perform the narrow-band to broad-band conversion, we used several sets of coefficients proposed by Weiss et al. (1999) and Liang et al. (1999) for atmospherically corrected data (see Table 1). They correspond to wave-bands and spectral filters somewhat different from PolDER bands. Nevertheless, we chose them since 
there was no proposition for PolDER.

[Table 1 about here.]

The approach used is similar to that of Price (1990). The hemispherical reflectance $\rho_{h, \lambda_{l}}\left(\theta_{s}, \varphi_{s}\right)$ for any wavelength $\lambda_{l} \in[300-3000] \mathrm{nm}$ is approximated as a linear combination of the estimated wave-band hemispherical reflectances $\rho_{h, \lambda_{j}}\left(\theta_{s}, \varphi_{s}\right)$ in the $p$ narrow-bands of the considered sensor:

$$
\rho_{h, \lambda_{l}}\left(\theta_{s}, \varphi_{s}\right)=\sum_{j=1}^{j=p} \beta_{\lambda_{l}, \lambda_{j}} \rho_{h, \lambda_{j}}\left(\theta_{s}, \varphi_{s}\right)
$$

This means that these $p$ estimates are assumed to contain the spectral information over the whole solar spectrum. From this assumption, it is thus possible to express the albedo as a linear combination of the $p$ hemispherical reflectance estimates:

$$
a\left(\theta_{s}, \varphi_{s}\right)=\sum_{j=1}^{j=p} \beta_{\lambda_{j}} \rho_{h, \lambda_{j}}\left(\theta_{s}, \varphi_{s}\right)
$$

The validity of the assumption of equation 5 has been verified by Weiss et al. (1999) using a simulated data base generated over the [400-2500] $\mathrm{nm}$ spectral range from the discrete ordinate radiative transfer model developed by Myneni et al. (1992). Finally, the integration over the [400-2500] nm spectral range provided three sets of coefficients $\beta_{\lambda_{j}}$ corresponding to different channel contributions. A similar set was proposed by Liang et al. (1999) for the MISR sensor, computed from a linear regression between albedo and bidirectional reflectances. The linear regression was performed on more than 100 observed reflectance spectra between 200 and $3000 \mathrm{~nm}$ that corresponded to vegetation, soil and snow. 


\section{Assessing the methods used for the albedo retrieval}

The proposed approach was assessed using several statistical tools. Both the Absolute / Relative Root Mean Square Error (ARMSE / RRMSE) and the Absolute / Relative Bias (ABias / RBias) between the predicted $(\mathrm{P})$ and observed $(\mathrm{O})$ variable were calculated as:

$$
\begin{array}{rlr}
\text { ARMSE } & =\sqrt{\frac{\sum_{k=1}^{k=m}\left(P_{k}-O_{k}\right)^{2}}{m}} \quad & \text { RRMSE }=\frac{\text { ARMSE }}{<O\rangle} \\
\text { ABias } & =\frac{\sum_{k=1}^{k=m} P_{k}-O_{k}}{m} & \text { RBias }=\frac{\text { ABias }}{\langle O\rangle}
\end{array}
$$

where $\langle O\rangle$ is the mean value of the $m$ estimates of the observed variable. In order to compare the different methods each other, we also calculated the ARMSE / RRMSE and the Absolute / Relative Bias (ABias / RBias) between two different predictions $P 1$ and $P 2$ :

$$
\begin{aligned}
\text { ARMSE } & =\sqrt{\frac{\sum_{k=1}^{k=m}\left(P 1_{k}-P 2_{k}\right)^{2}}{m}} \quad & \text { RRMSE }=\frac{\text { ARMSE }}{<P 1, P 2>} \\
\text { ABias } & =\frac{\sum_{k=1}^{k=m}\left(P 1_{k}-P 2_{k}\right)}{m} & \text { RBias }=\frac{\text { ABias }}{<P 1, P 2>}
\end{aligned}
$$

where $<P 1, P 2>$ is the mean value of the predictions $P 1$ and $P 2$ together. The slope $a$ and the offset $b$ of the linear regression between the predicted and observed variable provide an estimate of the systematic error induced by the method used:

$$
\bar{P}_{k}=a \times O_{k}+b
$$


The Absolute / Relative Unsystematic RMSE $\left(\mathrm{ARMSE}_{U} / \mathrm{RRMSE}_{U}\right.$ ) provides an estimate of the unsystematic error by calculating the scattering around the linear regression. It is expressed as the Root Mean Square Error between the predicted values computed from this regression $\bar{P}_{k}$ and the actual ones:

$$
A R M S E_{U}=\sqrt{\frac{\sum_{k=1}^{k=m}\left(\bar{P}_{k}-P_{k}\right)^{2}}{m}} \quad R R M S E_{U}=\frac{A R M S E_{U}}{<O>}
$$

Among the numerous PolDER data acquired during the experiment, three daily sets were removed because of instrumental troubles (wrong lens adjustment) or strong atmospheric perturbations (very hazy atmosphere). Besides, the kerneldriven model performances to adjust the observed BRDF were assessed over the whole experimental site, whereas we focused on pixels located on field measurements for further investigations.

\section{Performances of the linear kernel-driven BRDF models}

\section{Retrieval of the BRDF}

The BRDF retrieval performances of the kernel-driven models were evaluated by calculating the ARMSE and RRMSE between the observed and the retrieved bidirectional reflectances. Whatever were the model and the wave-band, the daily maps depicted large values for pixels located on both the Alpilles mountain chain and field borders (see for example Figure 2). The values observed for the pixels located on the mountain chain were explained by the inadequacy of the models when they were applied on inclined areas. The values observed on field borders 
were explained by the combination of registration inaccuracy and spatial variability. Indeed, the PolDER BRDF samplings were noisy on field borders whereas they depicted classical shapes within the fields. The daily performances were then computed over three pixel selections: the whole site without pixels located on the mountain chain ( $26 \%$ of pixels were removed), the whole site without pixels located on both the mountain chain and field borders (46\% of pixels were removed), and the pixels corresponding to the seven field measurement locations (on the center of the considered fields). Whatever were the model and the wave-band, we observed the same trend (see for example Table 2). First, the BRDF retrieval performances were slightly better after the removal of the field borders, with a decrease of the RRMSE between 0.5 and $2 \%$ depending on the PolDER channels. This small difference was explained by 1) the not systematic removal of the noisy pixels by the mask that did not account for the unsystematic error on image registration, and 2) the significant spatial variability inside some fields. Second, the RRMSE was almost divided by two when considering pixels located on field measurements, for which the perturbations due to the combination of spatial variability and registration inaccuracy were low since the neighborhood was homogeneous. Therefore, only the pixels located on field measurements were considered for further investigations.

[Figure 2 about here.]

[Table 2 about here.] 
A possible impact of the residual noises after atmospheric corrections was assessed by comparing for each model and each PolDER wave-band the daily RRMSE against the atmospheric variables used as SMAC inputs: aerosol optical depth at $550 \mathrm{~nm}$, atmospheric ozone concentration and atmospheric water vapor content (see an example in Figure 3). Whatever were the model and the waveband, this comparison showed that there was no obvious correlation between the daily performances and the atmospheric conditions. This has been confirmed by an analytical procedure that aimed at expressing the RRMSE as a linear combination of the atmospheric key variables using a pseudo matrix inversion. Therefore, the daily performances for a given wave-band were not first driven by possible residual noises after atmospheric corrections, these latter having a second or third order influence. The performances might be influenced by the inaccuracy on the sensor calibration since the procedure underlined a temporal drift (Leroy et al., 2001), whereas the capabilities of the models to fit the observed BRDF were certainly the main factor.

[Figure 3 about here.]

The evolution of the fitting performances according to the wave-band was similar from a model to another, with a decrease of the RRMSE as the wavelength increased except between the green and red channels (see for example Table 3). These results were similar to those reported by Baret et al. (1997), and were explained by a lower signal-to-noise ratio due to both the increase of the reflec- 
tance level and the decrease of the residual noise after atmospheric corrections (the aerosol scattering induced strong atmospheric perturbations in the blue channel that decreased with the wavelength). For a given wave-band, the performances were very close from a model to another. MRPV was the most sensitive model to the important signal-to-noise ratio occurring at $443 \mathrm{~nm}$, which was explained by its semi-linear formulation. Apart from the blue channel, the worst fits corresponded to Walthall since this model is purely empirical, and the best fits were provided by Li-Ross and MRPV. For the latter, well pronounced backscattering effects were observed at 550 and $670 \mathrm{~nm}$ (see for example Figure 4 and Figure 5).

[Table 3 about here.]

[Figure 4 about here.]

[Figure 5 about here.]

\section{Hemispherical reflectance estimation}

Since no field data of hemispherical reflectance were available, the unique way to assess the model performances at this step was to inter-compare the model estimates. The highest RRMSE values occurred in the blue channel whatever were the two inter-compared models, with significant values up to $25 \%$. The lowest scatters occurred in any one of the three other wave-bands according to the two inter-compared models (see an example in Table 4). Moreover, the range of the RRMSE over these three channels was very different from an inter-comparison to 
another. For example, the values ranged between 7 and $8.1 \%$ when considering LiRoss and Roujean, whereas they ranged between 5.5 and $11.5 \%$ for Li-Ross and Walthall. Therefore, the quality of the hemispherical reflectance estimates was not only driven by the BRDF interpolation performances since the fitting was better as the wavelength increased with similar residual errors from a model to another. Figure 6 displays the comparison between Li-Ross and Roujean estimates at $550 \mathrm{~nm}$. The over- or underestimations were significantly different according to the PolDER channels, with RBias ranging from 0 to $12 \%$ apart from the blue channel. However, it is interesting to notice that 1) Li-Ross provided systematically lower estimates than MRPV and Walthall, and 2) Roujean provided systematically lower estimates than MRPV. All the results presented here showed that the hemispherical reflectance estimates could be significantly different from a model to another, as observed by Privette et al. (1997) and Lucht (1998). This underlined the importance of the extrapolation performances of the kernel-driven models.

[Table 4 about here.]

[Figure 6 about here.]

\section{Assessment of the albedo retrievals}

Several albedo calculations were performed by considering the four linear kerneldriven BRDF models and the four sets of coefficients. An example of albedo map is given in Figure 7. Generally, the maps depicted albedo values between 0.1 and 0.4 . 
This important variability was explained by the simultaneous presence on the site of vegetative surfaces and bare soils. Table 5 and Table 6 display representative examples of the results we obtained when inter-comparing the albedo estimates. For a given set of coefficients, these estimates were systematically close from a kerneldriven model to another, with a RRMSE ranging between 5\% and $8 \%$ according to the used set. The discrepancies were ascribed to the differences between the hemispherical reflectance estimates. For a given kernel-driven model, the albedo values could be significantly different from a coefficient set to another, the RRMSE ranging between $2 \%$ and $19 \%$ according to the used kernel-driven model. The lowest estimates corresponded to set $\mathrm{n}^{\mathrm{o}} 4$. The estimates decreased when considering successively set $n^{0} 1, n^{0} 2$ and $n^{0} 3$, that corresponded to both a decrease of the red and NIR channel contributions and an increase of the green channel contribution. These results showed that the used method was mainly sensitive to the choice of a coefficient set. Besides, set $\mathrm{n}^{\mathrm{0}} 2$ and $\mathrm{n}^{\mathrm{0}} 3$ provided the closest estimates since they were very similar. This suggested that it might be possible to avoid the use of the blue channel for which many perturbations occurred.

[Figure 7 about here.]

[Table 5 about here.]

[Table 6 about here.] 
The validation consisted in comparing airborne PolDER albedo estimates with a footprint about $400 \mathrm{~m}^{2}$ against field measurements with footprints ranging from 1000 and $3000 \mathrm{~m}^{2}$. Therefore, we first assessed the impact of the spatial variability by computing the relative standard deviation (standard deviation / mean value) inside both $3 \times 3$ and $5 \times 5$ PolDER pixel windows. The results, between 1 and $2 \%$, underlined the negligible effect of the spatial variability around field measurement locations. The validation was next performed by extracting PolDER values through $3 \times 3$ pixel windows. To be consistent on the temporal aspect, the field measurements were averaged over the period of PolDER data acquisition (about 45 minutes). An example of comparison between field and airborne estimates is given in Figure 8. Whatever was the airborne albedo computation, we did not notice any different trend between Kipp and Skye estimates after the spectral correction of the latter. Representative results of the validation are given in Table 7 and Table 8 . Set $\mathrm{n}^{\mathrm{O}} 4$ provided estimates close to field measurements, whereas sets $\mathrm{n}^{\mathrm{0}} 1, \mathrm{n}^{\mathrm{0}} 2$ and $\mathrm{n}^{\mathrm{0}} 3$ overestimated field measurements. These overestimations were explained by the spectral range Weiss et al. (1999) used when calibrating the linear combination from a simulated database. Indeed, the simulations were performed over the [400-2500] nm spectral interval, while the whole solar spectrum ranges between 300 and $3000 \mathrm{~nm}$. Therefore, incident solar radiation was lower than the actual one, by 6-8\% referring to the works of Avaste et al. (1962). Since reflected solar radiation is low outside of the range $400-2500 \mathrm{~nm}$, this led to higher albedo 
values than the actual ones. The good results obtained with set $\mathrm{n}^{\mathrm{P}} 4$ were explained by 1) the similarity between the MISR and PolDER wave-bands (see Table 1), and 2) the spectral interval Liang et al. (1999) considered when calibrating the linear combination, i.e. [200-3000] $\mathrm{nm}$. We should notice that this set was calibrated using bidirectional reflectance data, which suggested that the directional aspect is of second order for the calibration. When considering set $n^{0} 4$, Walthall and Li-Ross models provided the best albedo values as compared to field data. This was explained by the robustness of Walthall when considering numerous situations, and could be explained by the good performances of Li-Ross for the hemispherical reflectance computation (Privette et al., 1997; Lucht, 1998). Finally, the two couples (Walthall, set $\left.n^{0} 4\right)$ and (Li-Ross, set $\left.n^{0} 4\right)$ either accounted the best for the numerous land use situations occurring throughout the ReSeDA experiment, or induced error compensations that provided the closest albedo values to the field ones.

[Figure 8 about here.]

[Table 7 about here.]

[Table 8 about here.]

In order to assess the accuracy that it would be possible to achieve after an in-situ calibration, we calculated the coefficients of the linear regression between predicted (or airborne) and observed (or field) estimates, as well as the absolute and relative unsystematic RMSE $\left(\mathrm{ARMSE}_{U}\right.$ and $\mathrm{RRMSE}_{U}$ ) (see for example Ta- 
ble 9). The coefficients of the linear regression for sets $n^{0} 1,2$ and 3 suggested that considering only hemispherical reflectances in red and NIR channels (set $\mathrm{r}^{\circledR} 1$ ) induced mainly an offset, while using more wave-bands (set $n^{0} 2$ and $n^{0} 3$ ) provided an overestimation of the low albedo values and an underestimation of the high ones. The same over- and underestimation trend was observed with set $\mathrm{n}^{\mathrm{4}} 4$. Finally, the $\mathrm{RRMSE}_{U}$ computations showed that the lowest unsystematic errors corresponded to Li-Ross and Walthall along with set no 4 RRMSE $_{U}$ about 8.1\% and $7.7 \%$ respectively).

[Table 9 about here.]

\section{Conclusion}

The objective of this study was to map albedo over agricultural surfaces using multi-directional and multi-spectral remote sensing data acquired during the ReSeDA experiment with the airborne PolDER sensor. The data set allowed to perform a validation over the whole cycles of several crops while problems induced by mixed pixel were reduced.

The multi-directional information was processed using the most classical linear kernel-driven BRDF models: Li-Ross, MRPV, Roujean and Walthall. The BRDF retrieval performances of the models were similar, with slightly better results from Li-Ross and MRPV. However, the quality of the hemispherical reflectance estimates was not only driven by the fitting performances, but also by the extrapo- 
lation capabilities of the models. The multi-spectral information was processed using several sets of coefficients to express the albedo as a linear combination of the wave-band hemispherical reflectances: three sets proposed for generic sensors, and one set proposed for the MISR sensor. The inter-comparison of the albedo estimates showed that the method was mainly sensitive to the choice of a coefficient set.

The best results obtained when validating the method against field measurements corresponded to both the Walthall and Li-Ross models along with the coefficient set proposed for MISR. This validation underlined the sensitivity of the coefficient set calibration to the used spectral range. A relative discrepancy at best about $9 \%$ was satisfactory as compared to the relative accuracy of the radiometric corrections of the PolDER data that was at least about 5\%. Further improvements should be performed, such as the calibration of the linear combination by accounting for the vegetative situation through either the NDVI (Song \& Gao, 1999) or the fractional vegetation cover. Moreover, it would be interesting to use linear combinations without considering the blue channel for which many perturbations occur due to the scattering by atmospheric aerosols.

It is important to notice that both the performances of the method at different steps and the final product quality were assessed over very homogeneous areas (in centers of fields were was located the ground measurements). However, the performances of the method were significantly poorer over the whole site, which 
was explained by the combination of the registration inaccuracy and the spatial variability. This underlined the importance of the registration accuracy when using high spatial resolution remote sensing data.

\section{Acknowledgements}

Financial support for this study was provided by EC in the frame of the WATERMED project (contract ICA3-CT-1999-00015). The Alpilles / ReSeDA project was funded by the EEC-DG XII (contract ENV4-CT96-0326-PL952071) and the French Programme National de Télédétection Spatiale and Programme National de Recherches en Hydrologie. The PolDER airborne sensor was provided by the Laboratoire d'Optique Atmosphérique, Lille, France. The author wishes to thank Mark Chopping for interesting suggestions.

\section{References}

Avaste, O., Moldau, H., \& Shifrin, K.S. (1962). Distribution spectrale des rayonnements directs et diffus. Instrumental and Physical Astronomy, 3, 44-57.

Baret, F., Weiss, M., Leroy, M., Hautecoeur, O., Santer, R., \& Bégué, A. (1997). Impact of surface anisotropies on the observation of optical imaging sensors. Final report, ESA contract 11341/95/NL/CN, ESA, ESTEC, the Netherlands.

Brown de Colstoun, E., Vermote, E., Walthall, C., Cialella, A., Halthore, R., \& Irons, J. (1996). Variability of BRDF with land cover type for the West central HAPEX-Sahel Super Site. In: IGARSS'96 (Lincoln, Nebraska, USA), International Geoscience and Remote Sensing Symposium (Piscataway, NJ: IEEE), pp. 1904-1907.

Chopping, M. (2000). Testing a LiSK BRDF Model with in Situ Bidirectional Reflectance Factor Measurements over Semiarid Grasslands. Remote Sensing of Environment, 74, 287-312. 
Deschamps, P.Y., Bréon, F.M., Leroy, M., Podaire, A., Bricaud, A. Buriez, J.C., \& Sèze, G. (1994). The PolDER mission : instrument characteristics and scientific objectives. IEEE Transactions on Geoscience and Remote Sensing, 32, 598-615.

Dickinson, R.E. (1992). Land surface. Cambridge University Press, New York.

Engelsen, O., Pinty, B., Verstraete, M., \& Martonchik, J.V. (1996). Parametric bidirectional reflectance factor models : evaluation, improvements and applications. Report eur16426en, European Commission, Joint Researches Center, Space Application Institute, ISPRA, Italy.

François, C., Ottlé, C., Olioso, A., Prévot, L., Bruguier, N., \& Ducros, Y. (2001). Correction of silicon sensors albedo measurements using a canopy radiative transfer model. Agronomie. Submitted.

Kustas, W.P., Moran, M.S., Humes, K.S., Stannard, D.I., Pinter, P.J., Hipps, L.E., Swiatek, E., \& Goodrich, D.C. (1994). Surface energy balance estimates at local and regional scales using optical remote sensing from an aircraft platform and atmospheric data collected over semiarid rangelands. Water Resources Research, $30,1241-1259$.

Leroy, M., Hautecoeur, O., Berthelot, B., \& Gu, X.F. (2001). The airborne PolDER data during the ReSeDA experiment. In: Physic and Chemistry of the Earth, special ReSeDA session. Submitted.

Liang, S., Strahler, A.H., \& Walthall, C.W. (1999). Retrieval of land surface albedo from satellite observations: A simulation study. Journal of Applied Meteorology, $38,712-725$.

Lucht, W. (1998). Expected retrieval accuracies of bidirectional reflectance and albedo from EOS-MODIS and MISR angular sampling. Journal of Geophysical Research, 103, 8763-8778.

Lucht, W. \& Roujean, J.L. (2000). Considerations in the parametric modeling of BRDF and albedo from multiangular satellite sensor observations. Remote Sensing Reviews, 18, 343-379.

Lucht, W., Schaaf, C.B., \& Strahler, A.H. (2000). An algorithm for the retrieval of albedo from space using semi-empirical BRDF models. IEEE Transaction on Geoscience and Remote Sensing, 38, 977-977.

Myneni, R.B., Asrar, G., \& Hall, F.G. (1992). A three-dimensional radiative transfer method for optical remote sensing of vegetated land surfaces. Remote Sensing of Environment, 41, 105-121.

Nilson, T. \& Kuusk, A. (1989). A reflectance model for the homogeneous plant canopy and its inversion. Remote Sensing of Environment, 27, 157-167. 
Olioso, A., Braud, I., Chanzy, A., Ducros, Y., Gaudu, J.C., Gonzales-Soza, E, Lewan, L., Marloie, O., Ottlé, C., Prévot, L., Autret, H., Bethenod, I., Bonnefond, J.M., Brugier, N., Calvet, J.C., Chauki, H., Goujet, R., Jongschaap, R., Kerr, Y., Lagouarde, J.P., Laurent, J.P., McAnneney, J, Moulin, S., Thony, J.L., Weiss, M., \& Wigneron, J.-P. (2001). SVAT modeling over the AlpillesReSeDA experiment: experimental setup for monitoring energy and mass transfers. Agronomie. Submitted.

Olioso, A., Chauki, H., Courault, D., \& Wigneron, J.P. (1999). Estimation of evapotranspiration and photo-synthesis by assimilation of remote sensing data into SVAT models. Remote Sensing of Environment, 68, 341-356.

Pinty, B. \& Verstraete, M. (1992). On the design and validation of surface bidirectional reflectance and albedo model. Remote Sensing of Environment, 41, $155-167$.

Pragnère, A., Baret, F., Weiss, M., Myneni, R., Knyazikhin, Y., \& Wang, L.B. (1999). Comparison of three radiative transfer model inversion techniques to estimate canopy biophysical variables from remote sensing data. In: Proceedings of IEEE 1999, 28 June - 2 July 1999, Hamburg, vol. 2, pp. 1093-1095.

Prévot, L., Baret, F., Chanzy, A., Olioso, A., Wigneron, J.P., Autret, H., Baudin, F., Bessemoulin, P., Bethenod, O., Blamont, D., Blavoux, B., Bonnefond, J.M., Boubkraoui, S., Bouman, B.A.M., Braud, I., Bruguier, N., Calvet, J.C., Caselles, V., Chauki, H., Clevers, J.G.P.W., Coll, C., Company, A., Courault, D., Dedieu, G., Degenne, P., Delécolle, R., Denis, H., Desprats, J.F., Ducros, Y., Dyer, D., Fies, J.C., Fischer, A., Francois, C., Gaudu, J.C., Gonzalez, E., Gouget, R., Gu, X.F., Guérif, M., Hanocq, J.F., Hautecoeur, J.F., Haverkamp, R., Hobbs, S., Jacob, F., Jeansoulin, R., Jongschaap, R.E.E., Kerr, Y., King, C., Laborie, P., Lagouarde, J.P., Laques, A.E., Larcena, D., Laurent, G., Laurent, J.P., Leroy, M., McAneney, J., Macelloni, G., Moulin, S., Noilhan, J., Ottlé, C., Paloscia, S., Pampaloni, P., Podvin, T., Quaracino, F., Roujean, J.L., Rozier, C., Ruisi, R., Susini, C., Taconet, O., Tallet, N., Thony, J.L., Travi, Y., Van Leewen, H., Vauclin, M., Vidal-Madjar, D, Vonder, O.W., \& Weiss, M. (1998). Assimilation of multi-sensor and multi-temporal remote sensing data to monitor vegetation and soil: the Alpilles ReSeDA project. In: IGARSS'98 International Geoscience and Remote Sensing Symposium, Tsang L. Ed., IEEE, Institute of Electrical and Electronics Engineers, Piscataway (USA), Sensing and managing the environment, vol. 5, pp. 2399-2401.

Price, J.C. (1990). Information content of soil spectra. Remote Sensing of the Environment, 33, 113-121.

Privette, J.L., Eck, T.F., \& Deering, D.W. (1997). Estimating spectral albedo and nadir reflectance through inversion of simple BRDF models with 
AVHRR/MODIS-like data. Journal of Geophysical Research, 102, 2952929542.

Rahman, H. \& Dedieu, G. (1994). SMAC : a Simplified Method for the Atmospheric Correction of satellite measurements in the solar spectrum. International Journal of Remote Sensing, 16, 123-143.

Roujean, J.L., Leroy, M., \& Deschamps, P.Y. (1992). A bidirectional reflectance model of the Earth's surface for the correction of remote sensing data. Journal of Geophysical Research, 97, 20455-20468.

Roujean, J.L., Tanre, D., Bréon, F.-M., \& Deuzé, J.L. (1997). Retrieval of land surface parameters from airborne PolDER bidirectional reflectance distribution function during HAPEX-Sahel. Journal of Geophysical Research, 102, 1121011218.

Sellers, P.J. (1993). Remote sensing of the land surface for studies of global change. International Satellite Land Surface Climatology Project Report, NASA/GSFC, Columbia, MD.

Song, J. \& Gao, W. (1999). An improved method to derive surface albedo from narrow-band AVHRR satellite data: narrow-band to broadband conversion. Journal of Applied Meteorology, 38, 239-249.

Strahler, A.H., Schaaf, C.B., Muller, J.-P., Wanner, W., Barnsley, M.J., d'Entremont, R., B., Hu, Lewis, P., Li, X., \& Ruise De Lope, E.V. (1996). MODIS BRDF / Albedo product : algorithm theoretical basis document. NASA EOS-MODIS doc. incl. update, version 4.0, $252 \mathrm{pp}$, NASA/GSFC, Greenbelt MD, USA.

Verhoef, W. (1984). Light scattering by leaf layers with application to canopy reflectance modeling : the SAIL model. Remote Sensing of Environment, 16, $125-141$.

Vermote, E., Tanré, D., Deuzé, J.L., \& Morcrette, J.J. (1997). Second simulation of the satellite signal in the solar spectrum: an overview. IEEE Transactions on Geoscience and Remote Sensing, 35, 675-686.

Walthall, C.L., Norman, J.M., Welles, G., Campbell, G., \& Blad, G.L. (1985). Simple equation to approximate the bidirectional reflectance from vegetative canopies and bare soil surfaces. Applied Optics, 24, 383-387.

Walthall, C.L., Roujean, J.L., \& Morisette, J. (2000). Field and landscape BRDF optical wavelength measurements: experiences, technique and the future. $R e$ mote Sensing Reviews, 18, 503-531. 
Wanner, W., Li, X., \& Strahler, A.H. (1995). On the derivation of kernels for kernel-driven models of bidirectional reflectance. Journal of Geophysical Research, 100, 21077-21089.

Wanner, W., Strahler, A.H., Hu, B., Lewis, P., Muller, J.-P., Li, X., Barker Schaaf, C, \& Barnsley, M. (1997). Global retrieval of bidirectional reflectance and albedo over land from EOS MODIS and MISR data: theory and algorithm. Journal of Geophysical Research, 102, 17143-17161.

Weiss, M., Baret, F., Leroy, M., Bégué, A., Hautecoeur, O., \& Santer, R. (1999). Hemispherical reflectance and albedo estimate from the accumulation of acrosstrack sun-synchronous satellite data. Journal of Geophysical Research, 104, 22221-22232.

Weiss, M., Jacob, F., Baret, F., Pragnère, A., Leroy, M., Hautecoeur, O., Prévot, L., \& Bruguier, N. (2001). Evaluation of kernel-driven BRDF models for the normalization of Alpilles/ReSeDA PolDER data. Agronomie. Submitted. 


\section{List of Figures}

1 Land use map of the ReSeDA experimental site. . . . . . . . . . . .

2 Map of the RRMSE (\%) between the observed and adjusted BRDFs over the whole ReSeDA experimental site on March, 12th at $670 \mathrm{~nm}$ when using the MRPV model. . . . . . . . . . . . . . . . . . .

3 Top: Daily values of the RRMSE (\%) between the observed and retrieved BRDFs at both 443 and $865 \mathrm{~nm}$ when using the MRPV model. Bottom: Daily values of the atmospheric transmittance at $550 \mathrm{~nm} \tau_{a}$, the atmospheric ozone concentration $\left[\mathrm{O}_{3}\right]$, and the atmospheric water vapor content $W$ (from Leroy et al. (2001)). The days of the experiment are given in Month/Day. . . . . . . . . . . . . . . . . . . .

4 Comparison of the retrieved BRDFs at $670 \mathrm{~nm}$ from the four kerneldriven models against PolDER data when considering the flight line closest to the solar plan. The observed surface is a bare soil on March, 26th. Solar view angle about $43.9^{\circ}$. The backscattering direction is on left. . .

5 Comparison of the retrieved BRDFs at $550 \mathrm{~nm}$ from the four kerneldriven models against PolDER data when considering the flight line closest to the solar plan. The observed surface is a senescent sunflower field on July, 07 th. Solar view angle about $23^{\circ}$. The backscattering direction is on left. . . . . . . . . . . . . . . . . .

6 Comparison between the Roujean and Li-Ross hemispherical reflectance estimates at $550 \mathrm{~nm} . \ldots \ldots \ldots$. . . . . . . . . . Albedo map on April, 10th using the Walthall model and the coefficient set $n^{0} 1$. The Alpilles mountain chain has been removed. We should notice the presence of well developed wheat and bare soil. . . . . . . . . Comparison between field and airborne albedo estimates considering the Walthall model and the coefficient set $\mathrm{n}^{\mathrm{O}} 4 \ldots \ldots \ldots \ldots \ldots$ 


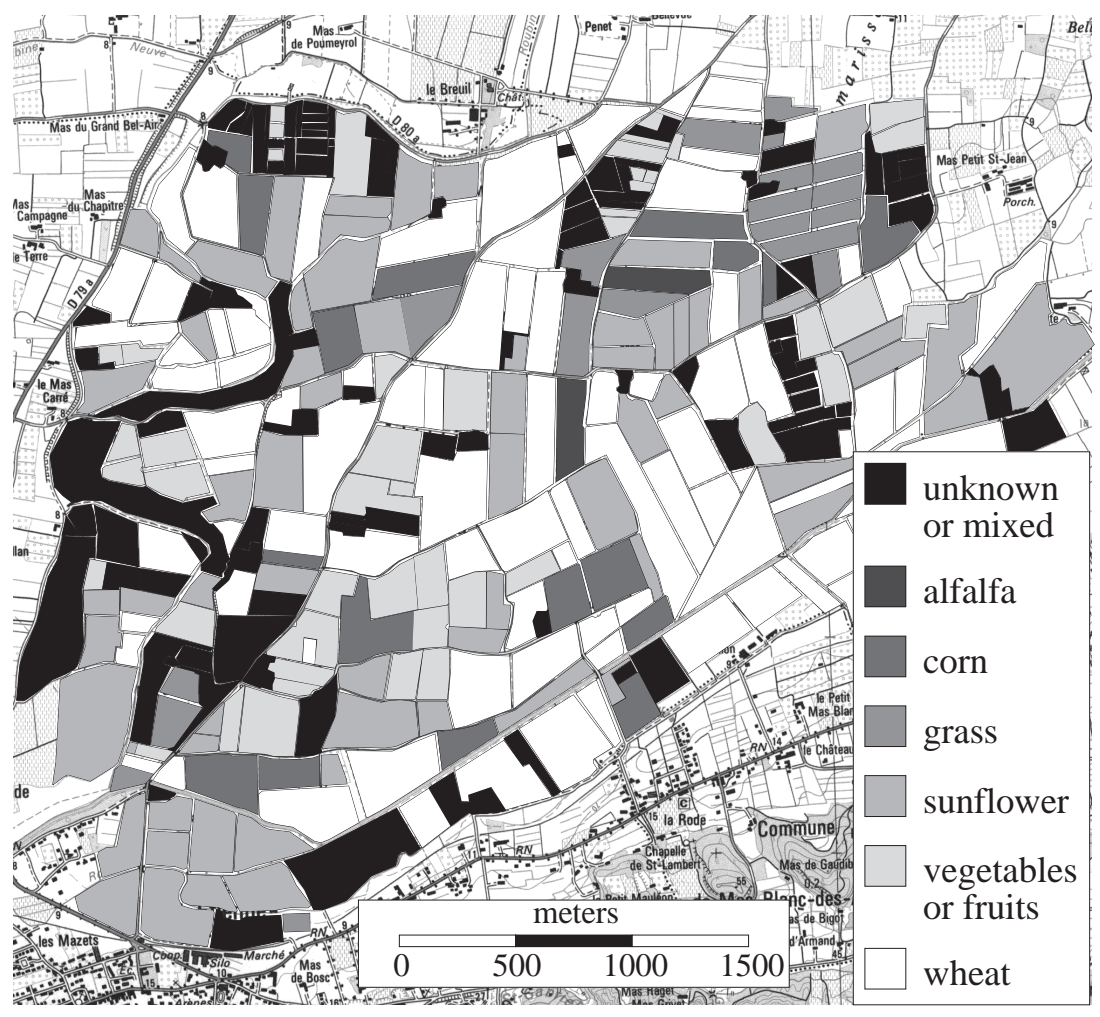

Figure 1: Land use map of the ReSeDA experimental site. 


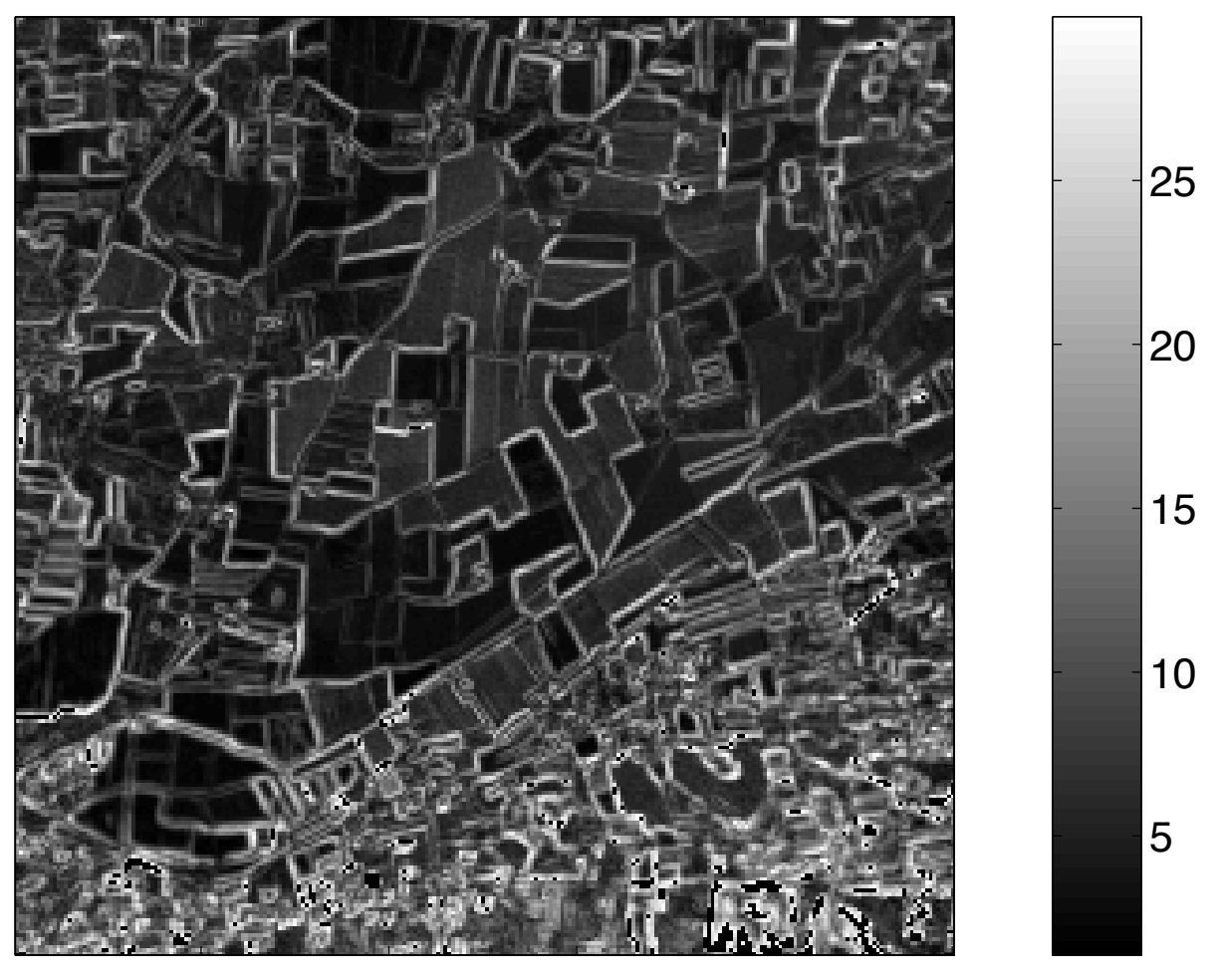

Figure 2: Map of the RRMSE (\%) between the observed and adjusted BRDFs over the whole ReSeDA experimental site on March, 12th at $670 \mathrm{~nm}$ when using the MRPV model. 

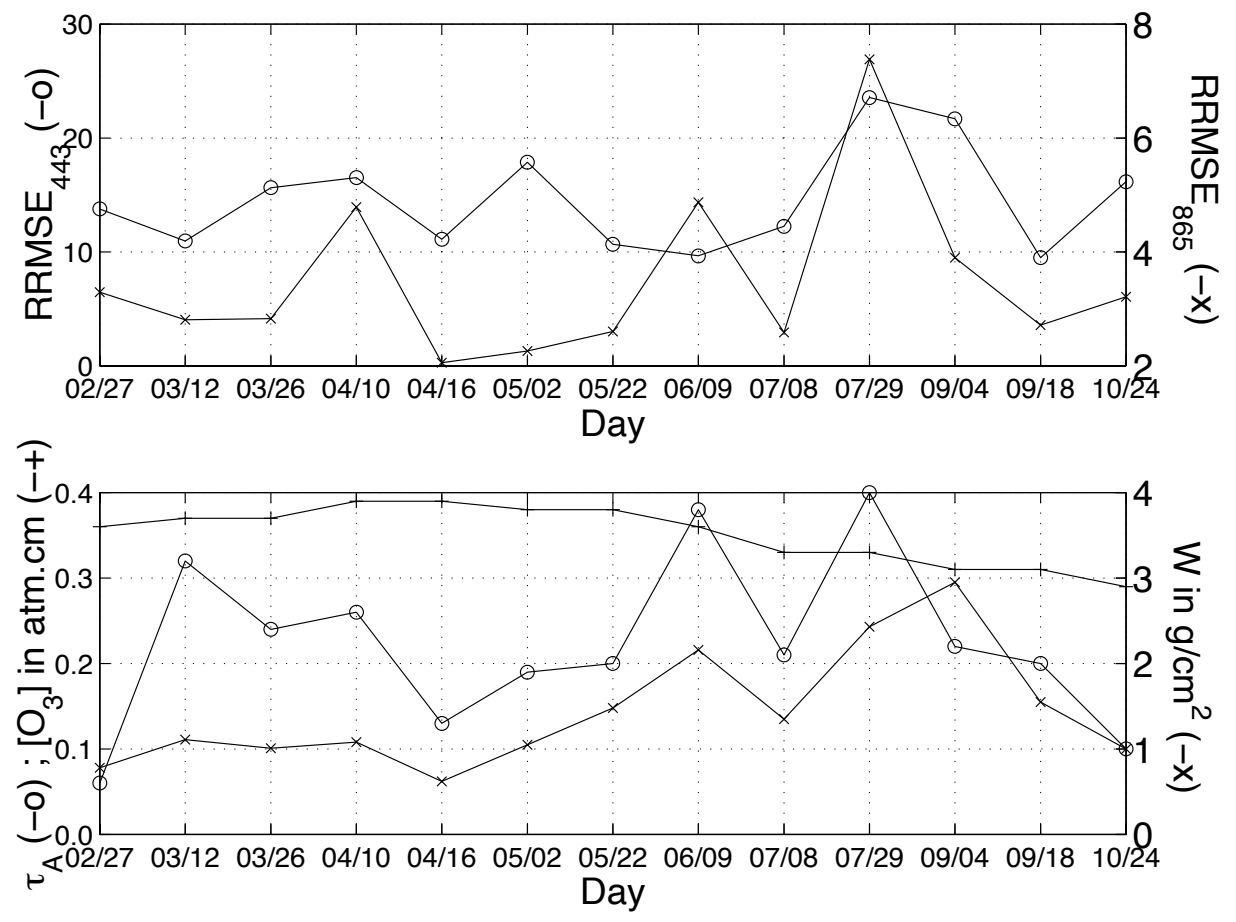

Figure 3: Top: Daily values of the RRMSE (\%) between the observed and retrieved BRDFs at both 443 and $865 \mathrm{~nm}$ when using the MRPV model. Bottom: Daily values of the atmospheric transmittance at $550 \mathrm{~nm} \tau_{a}$, the atmospheric ozone concentration $\left[\mathrm{O}_{3}\right]$, and the atmospheric water vapor content $W$ (from Leroy et al. (2001)). The days of the experiment are given in Month/Day. 


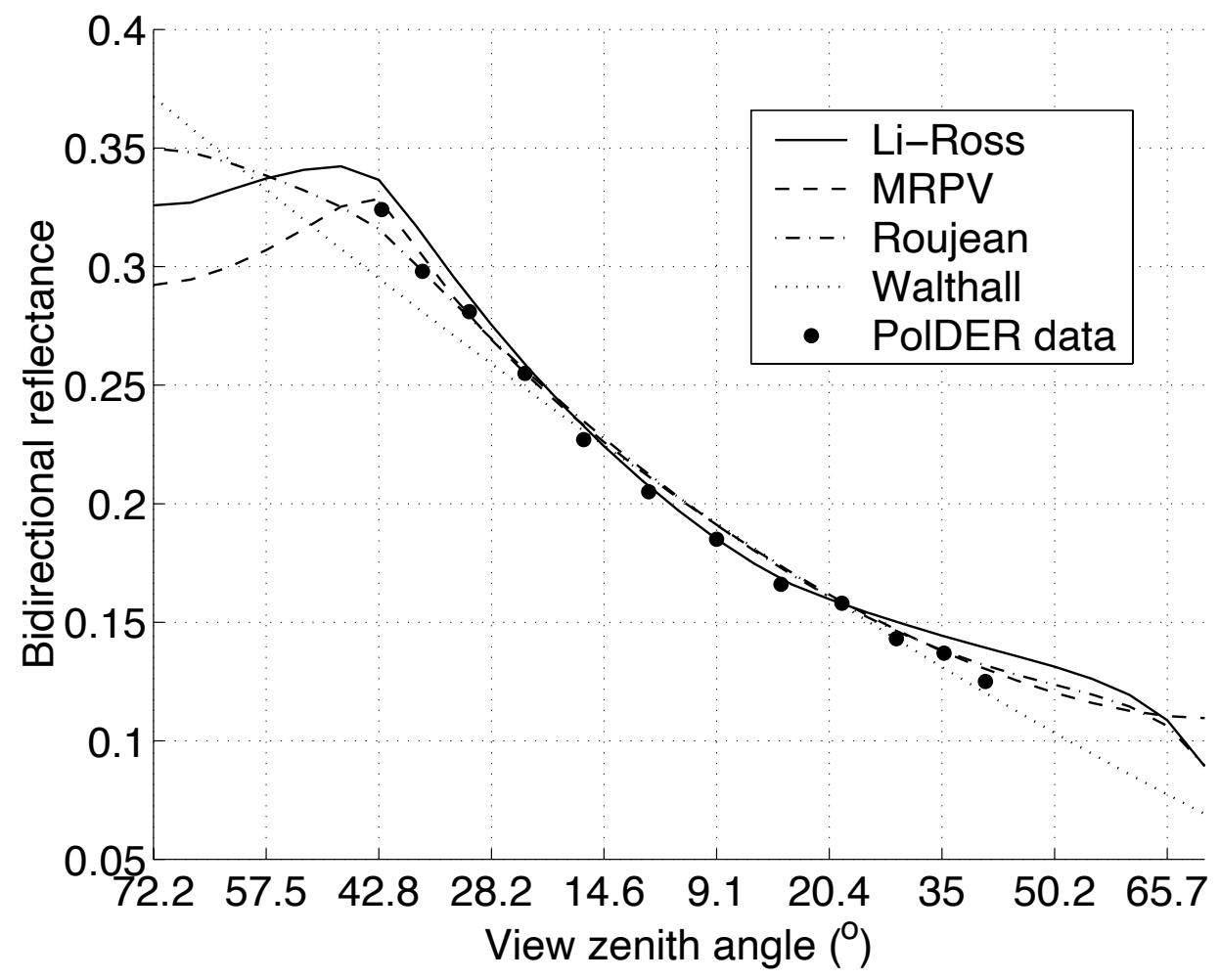

Figure 4: Comparison of the retrieved BRDFs at $670 \mathrm{~nm}$ from the four kernel-driven models against PolDER data when considering the flight line closest to the solar plan. The observed surface is a bare soil on March, 26th. Solar view angle about $43.9^{\circ}$. The backscattering direction is on left. 


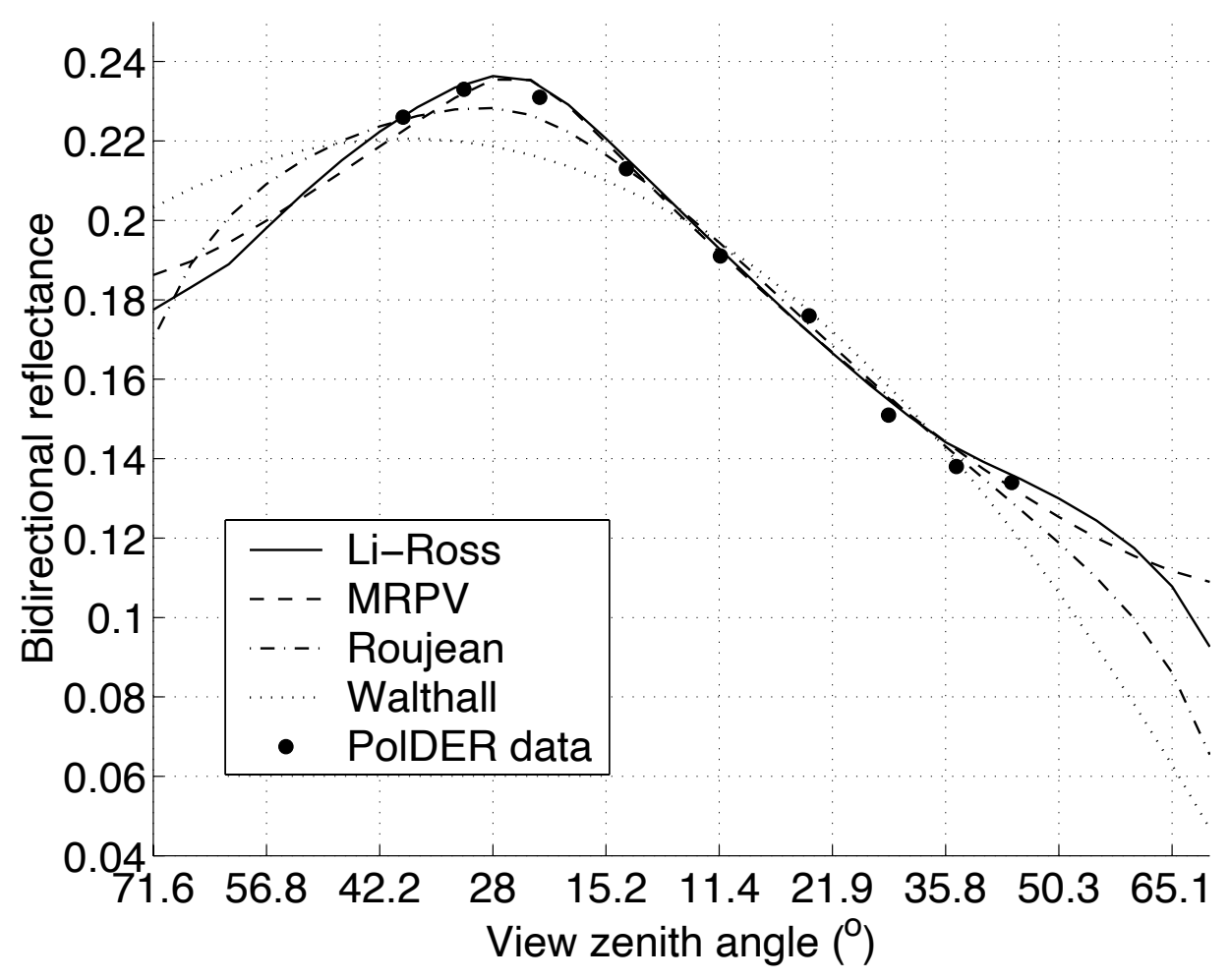

Figure 5: Comparison of the retrieved BRDFs at $550 \mathrm{~nm}$ from the four kernel-driven models against PolDER data when considering the flight line closest to the solar plan. The observed surface is a senescent sunflower field on July, 07th. Solar view angle about $23^{\circ}$. The backscattering direction is on left. 


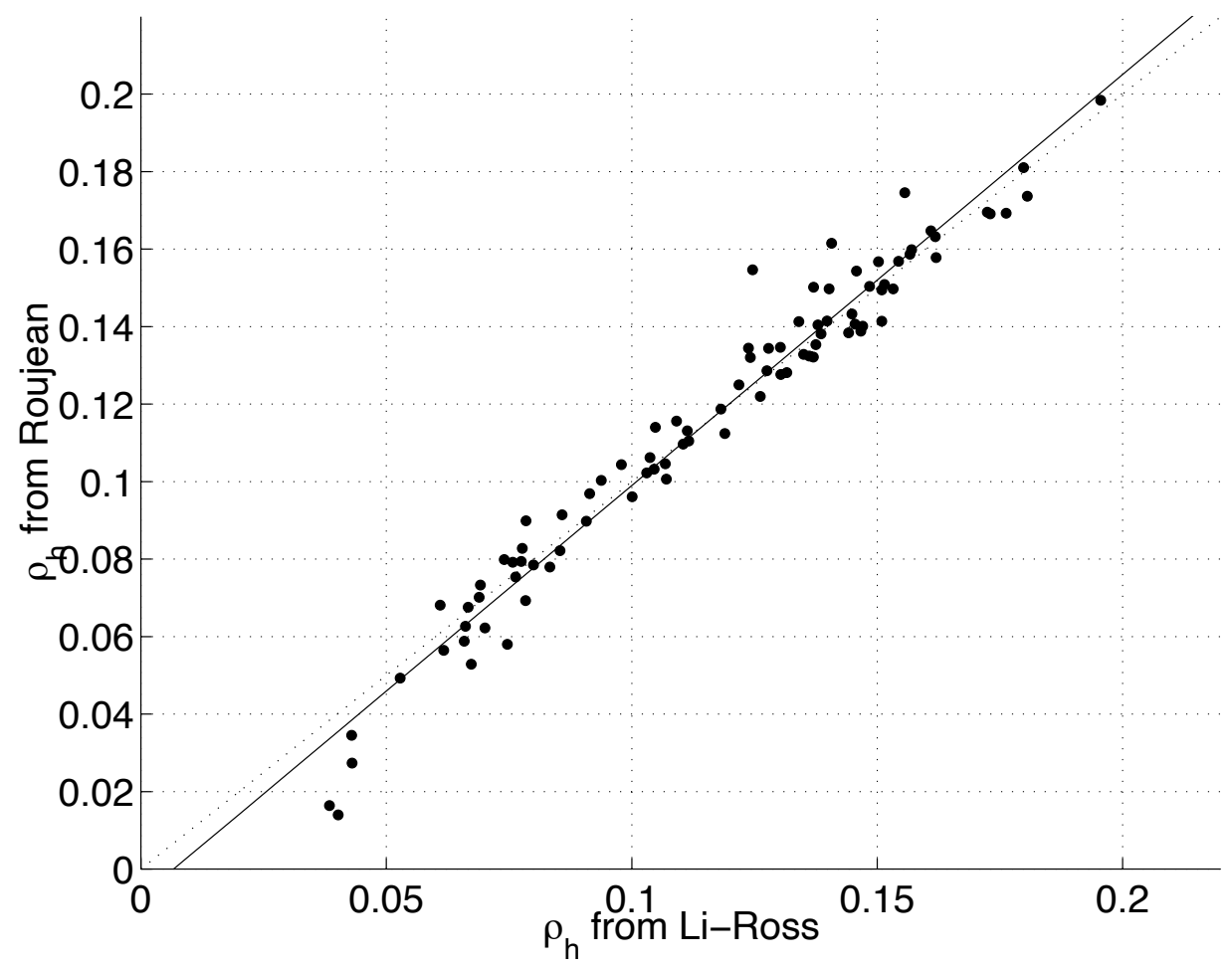

Figure 6: Comparison between the Roujean and Li-Ross hemispherical reflectance estimates at $550 \mathrm{~nm}$. 

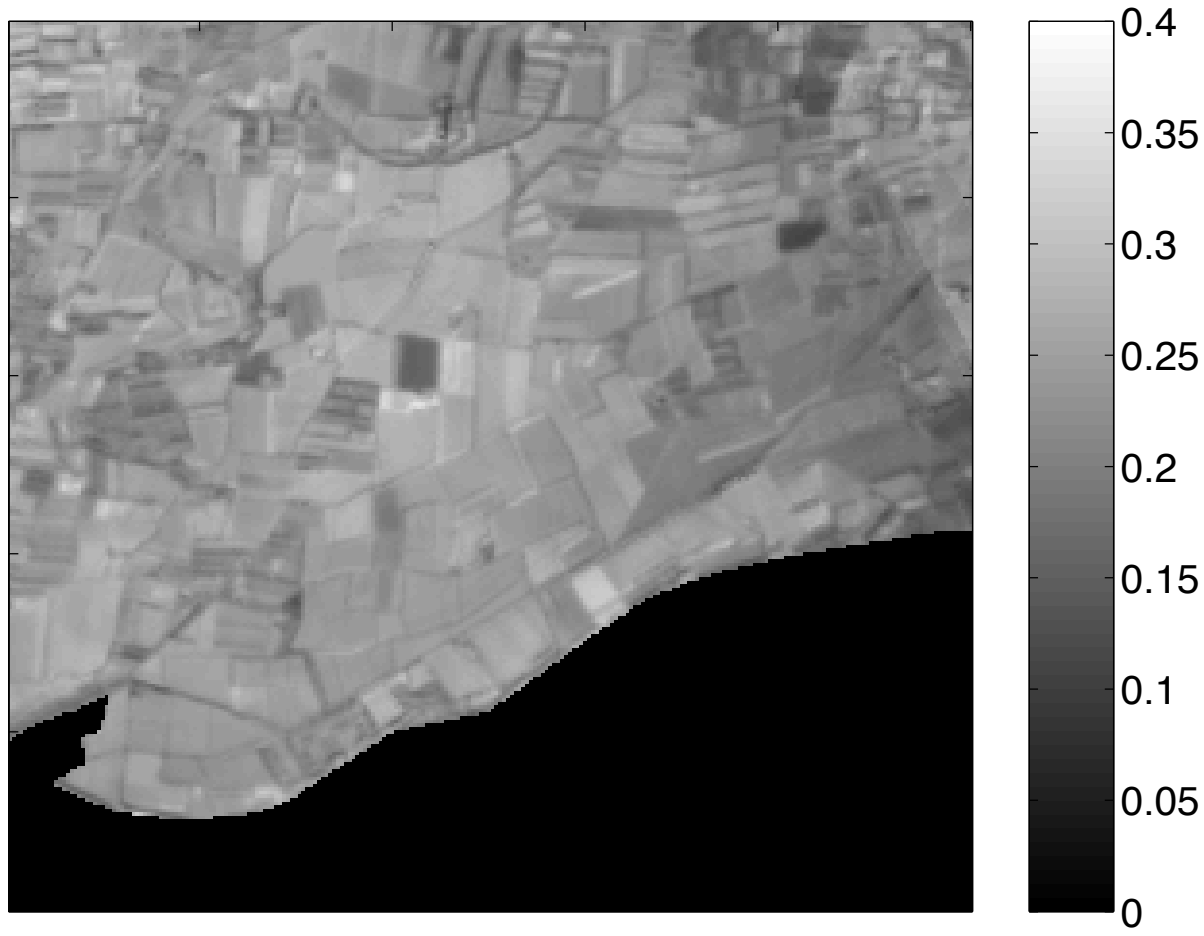

Figure 7: Albedo map on April, 10th using the Walthall model and the coefficient $\operatorname{set} \mathrm{n}^{\mathrm{o}} 1$. The Alpilles mountain chain has been removed. We should notice the presence of well developed wheat and bare soil. 


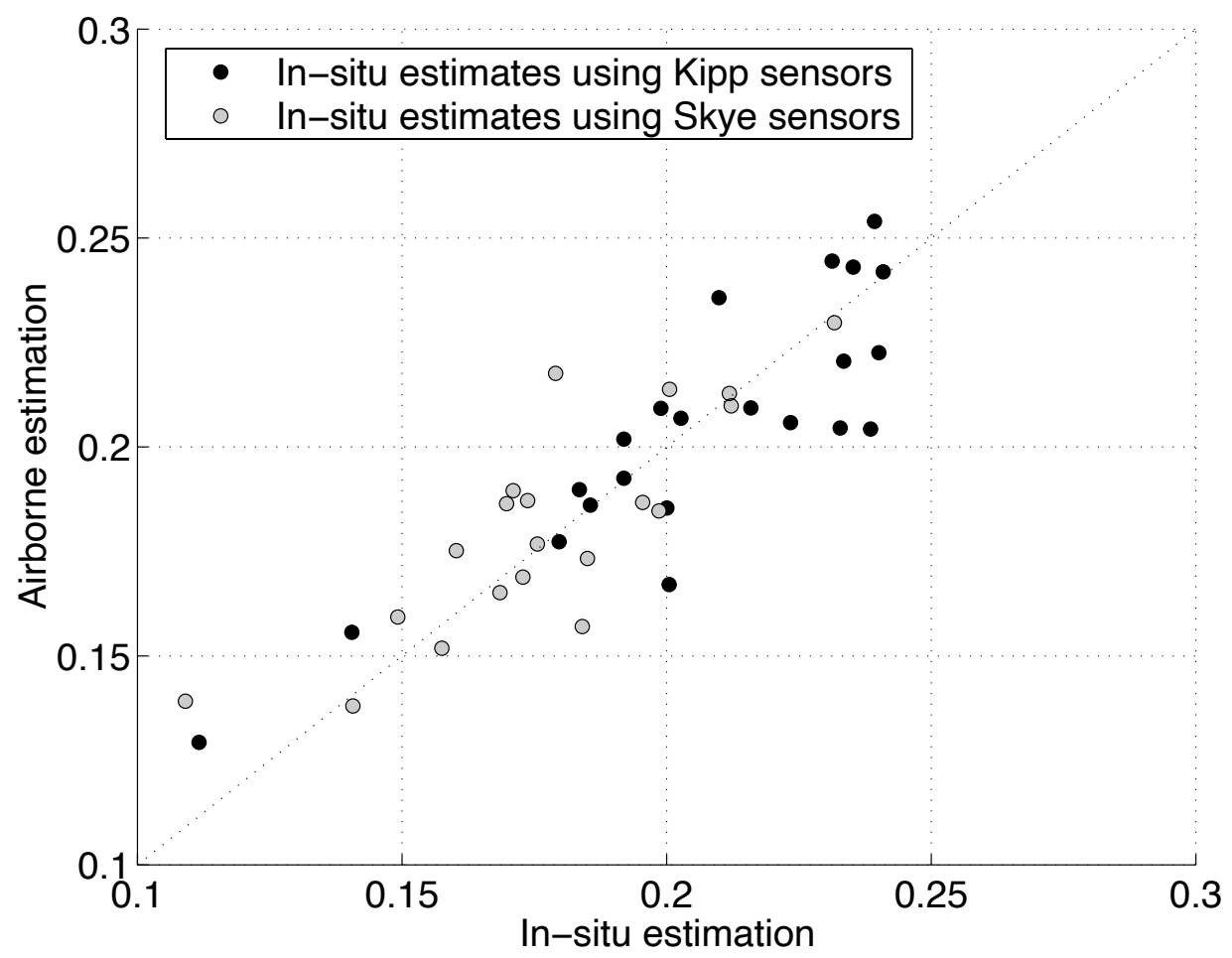

Figure 8: Comparison between field and airborne albedo estimates considering the Walthall model and the coefficient set $\mathrm{n}^{\mathrm{O}} 4$. 


\section{List of Tables}

1 Sets of coefficients used to compute the albedo as a linear combination of wave-band hemispherical reflectances. The wave-band limits (in $\mathrm{nm}$ ) indicate respectively the wavelengths Weiss et al. (1999) considered for generic sensors ( $\operatorname{set} \mathrm{n}^{\mathrm{o}} 1,2,3$ ), the nominal wave-bands Liang et al.

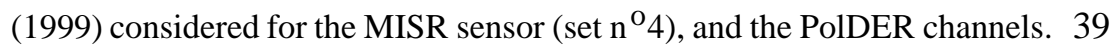

2 Absolute and relative RMSE between the observed and the retrieved BRDFs from Li-Ross model when considering the three pixel selections. Selection 1 corresponds to the whole site without pixels located on the mountain chain. Selection 2 corresponds to the whole site without pixels located on both the mountain chain and field borders. Selection 3 corresponds to pixels located on in-situ measurements. . . . . . . . . . . . Absolute and relative RMSE between the observed and adjusted BRDFs from the four kernel-driven models according to the PolDER channels. .

4 Comparison between the hemispherical reflectance estimates from $\mathrm{Li}$ Ross and MRPV according to the four PolDER channels. Corr. Coef. means Correlation Coefficient. . . . . . . . . . . . . .

5 Comparison between the albedo estimates for $\operatorname{set}^{0} 1$ and the four kerneldriven models. According to the chosen nomenclature, albedo estimates from the first BRDF model (respectively the second) correspond to the prediction $\mathrm{P} 1$ (respectively prediction $\mathrm{P} 2)$. . . . . . . . . . . .

6 Comparison between the albedo estimates for the Li-Ross model and the four sets of coefficients. According to the chosen nomenclature, albedo estimates from the first BRDF model (respectively the second) correspond to the prediction $\mathrm{P} 1$ (respectively prediction $\mathrm{P} 2$ ). . . . . . . . . Absolute and relative RMSE and Bias between airborne and field albedo estimates for the four sets of coefficients and the MRPV model. . . . .

8 Absolute and relative RMSE and Bias between airborne and field albedo estimates for the four kernel-driven models and set of coefficients $n^{0} 4$. .

Coefficients of the linear regression between field and airborne estimates of the albedo (a: slope, b: offset), and absolute/relative RMSE between PolDER estimates and the linear regression $\left(\mathrm{A} / \mathrm{RRMSE}_{U}\right) \ldots \ldots$. . . . 


\begin{tabular}{|c|c|c|c|c|c|}
\hline & Blue & Green & Red & NIR & Offset \\
\hline $\begin{array}{l}\text { Considered } \\
\text { wavelengths }\end{array}$ & 445 & 560 & 665 & 855 & \\
\hline Set $^{0}{ }^{0} 1$ & - & - & 0.57 & 0.46 & - \\
\hline Set $n^{0} 2$ & - & 0.68 & 0.08 & 0.35 & - \\
\hline Set $n^{0} 3$ & 0.06 & 0.69 & 0.001 & 0.35 & - \\
\hline $\begin{array}{c}\text { MISR } \\
\text { wave-bands }\end{array}$ & $426-467$ & $544-571$ & $662-682$ & $847-886$ & \\
\hline Set $n^{0} 4$ & 0.1587 & -0.2463 & 0.5442 & 0.3748 & 0.0149 \\
\hline $\begin{array}{c}\text { PolDER } \\
\text { wave-bands }\end{array}$ & $423-463$ & $530-570$ & $650-690$ & $845-885$ & \\
\hline
\end{tabular}

Table 1: Sets of coefficients used to compute the albedo as a linear combination of waveband hemispherical reflectances. The wave-band limits (in $\mathrm{nm}$ ) indicate respectively the wavelengths Weiss et al. (1999) considered for generic sensors ( $\operatorname{set} n^{0} 1,2,3$ ), the nominal wave-bands Liang et al. (1999) considered for the MISR sensor $\left({\operatorname{set~}{ }^{\circ}}^{\circ}\right.$ ), and the PolDER channels. 


\begin{tabular}{c||c||c|c|c} 
Channel & Error & Selection 1 & Selection 2 & Selection 3 \\
\hline \hline Blue & ARMSE & 0.0119 & 0.0110 & 0.0073 \\
$(443 \mathrm{~nm})$ & RRMSE & $20.0 \%$ & $18.3 \%$ & $11.1 \%$ \\
\hline Green & ARMSE & 0.0123 & 0.0115 & 0.0070 \\
$(550 \mathrm{~nm})$ & RRMSE & $10.6 \%$ & $09.7 \%$ & $05.5 \%$ \\
\hline Red & ARMSE & 0.0125 & 0.0118 & 0.0070 \\
$(670 \mathrm{~nm})$ & RRMSE & $10.3 \%$ & $09.5 \%$ & $05.2 \%$ \\
\hline NIR & ARMSE & 0.0242 & 0.0222 & 0.0134 \\
$(865 \mathrm{~nm})$ & RRMSE & $07.0 \%$ & $06.5 \%$ & $03.4 \%$
\end{tabular}

Table 2: Absolute and relative RMSE between the observed and the retrieved BRDFs from Li-Ross model when considering the three pixel selections. Selection 1 corresponds to the whole site without pixels located on the mountain chain. Selection 2 corresponds to the whole site without pixels located on both the mountain chain and field borders. Selection 3 corresponds to pixels located on in-situ measurements. 


\begin{tabular}{c||c||c|c|c|c}
\multirow{2}{*}{ Model } & Error & $\begin{array}{c}\text { Blue } \\
(443 \mathrm{~nm})\end{array}$ & $\begin{array}{c}\text { Green } \\
(550 \mathrm{~nm})\end{array}$ & $\begin{array}{c}\text { Red } \\
(670 \mathrm{~nm})\end{array}$ & $\begin{array}{c}\text { NIR } \\
(865 \mathrm{~nm})\end{array}$ \\
\hline \hline \multirow{2}{*}{ Li-Ross } & ARMSE & 0.0073 & 0.0070 & 0.0070 & 0.0134 \\
& RRMSE & $11.1 \%$ & $05.5 \%$ & $05.2 \%$ & $03.9 \%$ \\
\hline \multirow{2}{*}{ MRPV } & ARMSE & 0.0096 & 0.0069 & 0.0069 & 0.0119 \\
& RRMSE & $14.6 \%$ & $05.4 \%$ & $05.1 \%$ & $03.5 \%$ \\
\hline \multirow{2}{*}{ Roujean } & ARMSE & 0.0065 & 0.0075 & 0.0077 & 0.0135 \\
& RRMSE & $10.0 \%$ & $05.9 \%$ & $05.7 \%$ & $04.0 \%$ \\
\hline \multirow{2}{*}{ Walthall } & ARMSE & 0.0079 & 0.0105 & 0.0108 & 0.0171 \\
& RRMSE & $12.1 \%$ & $08.2 \%$ & $08.0 \%$ & $05.0 \%$
\end{tabular}

Table 3: Absolute and relative RMSE between the observed and adjusted BRDFs from the four kernel-driven models according to the PolDER channels. 


\begin{tabular}{l||c|c|c|c} 
Channel & $\begin{array}{c}\text { Blue } \\
(443 \mathrm{~nm})\end{array}$ & $\begin{array}{c}\text { Green } \\
(550 \mathrm{~nm})\end{array}$ & $\begin{array}{c}\text { Red } \\
(670 \mathrm{~nm})\end{array}$ & $\begin{array}{c}\text { NIR } \\
(865 \mathrm{~nm})\end{array}$ \\
\hline \hline ARMSE & 0.0078 & 0.0098 & 0.0124 & 0.0295 \\
\hline RRMSE & $12.8 \%$ & $08.1 \%$ & $10.0 \%$ & $08.3 \%$ \\
\hline Corr. Coef. & 0.9671 & 0.9891 & 0.9907 & 0.9851
\end{tabular}

Table 4: Comparison between the hemispherical reflectance estimates from Li-Ross and MRPV according to the four PolDER channels. Corr. Coef. means Correlation Coefficient. 


\begin{tabular}{c|c||c|c|c|c|c}
$\begin{array}{c}\text { First } \\
\text { Model }\end{array}$ & $\begin{array}{c}\text { Second } \\
\text { Model }\end{array}$ & ARMSE & RRMSE & $\begin{array}{c}\text { Corr. } \\
\text { Coef. }\end{array}$ & ABias & RBias \\
\hline \hline Li-Ross & MRPV & 0.0168 & $07.3 \%$ & 0.9588 & -0.0139 & $-06.0 \%$ \\
\hline MRPV & Roujean & 0.0113 & $04.8 \%$ & 0.9760 & 0.0075 & $03.2 \%$ \\
\hline Roujean & Walthall & 0.0162 & $07.0 \%$ & 0.9091 & -0.0053 & $-02.3 \%$
\end{tabular}

Table 5: Comparison between the albedo estimates for $\operatorname{set}^{0} 1$ and the four kernel-driven models. According to the chosen nomenclature, albedo estimates from the first BRDF model (respectively the second) correspond to the prediction P1 (respectively prediction P2). 


\begin{tabular}{c|c||c|c|c|c|c}
$\begin{array}{c}\text { First } \\
\text { Set }\end{array}$ & $\begin{array}{c}\text { Second } \\
\text { Set }\end{array}$ & ARMSE & RRMSE & $\begin{array}{c}\text { Corr } \\
\text { Coef. }\end{array}$ & ABias & RBias \\
\hline \hline Set $\mathrm{n}^{\mathrm{o}} 1$ & Set $\mathrm{n}^{\mathrm{o}} 2$ & 0.0178 & $08.3 \%$ & 0.9599 & 0.0153 & $07.1 \%$ \\
\hline Set $\mathrm{n}^{\mathrm{o}} 2$ & Set $\mathrm{n}^{\mathrm{O}} 3$ & 0.0055 & $02.7 \%$ & 0.9963 & 0.0048 & $02.3 \%$ \\
\hline Set $\mathrm{n}^{\mathrm{o}} 3$ & Set $\mathrm{n}^{\mathrm{O}} 4$ & 0.0202 & $10.3 \%$ & 0.9377 & 0.0167 & $08.5 \%$
\end{tabular}

Table 6: Comparison between the albedo estimates for the Li-Ross model and the four sets of coefficients. According to the chosen nomenclature, albedo estimates from the first BRDF model (respectively the second) correspond to the prediction P1 (respectively prediction $\mathrm{P} 2$ ). 


\begin{tabular}{c||c|c|c|c} 
Coefficient set & ARMSE & RRMSE & ABias & RBias \\
\hline \hline Set $\mathrm{n}^{\mathrm{o}} 1$ & 0.0530 & $27.2 \%$ & 0.0480 & $24.6 \%$ \\
\hline Set $\mathrm{n}^{\mathrm{o}} 2$ & 0.0345 & $17.7 \%$ & 0.0285 & $14.7 \%$ \\
\hline Set $\mathrm{n}^{\mathrm{o}} 3$ & 0.0320 & $16.4 \%$ & 0.0251 & $12.8 \%$ \\
\hline Set $\mathrm{n}^{\mathrm{o}} 4$ & 0.0216 & $11.1 \%$ & 0.0065 & $03.3 \%$
\end{tabular}

Table 7: Absolute and relative RMSE and Bias between airborne and field albedo estimates for the four sets of coefficients and the MRPV model. 


\begin{tabular}{c||c|c|c|c} 
BRDF model & ARMSE & RRMSE & ABias & RBias \\
\hline \hline Li-Ross & 0.0188 & $09.7 \%$ & -0.0051 & $-02.6 \%$ \\
\hline MRPV & 0.0216 & $11.1 \%$ & 0.0065 & $03.3 \%$ \\
\hline Roujean & 0.0226 & $11.7 \%$ & 0.0020 & $01.0 \%$ \\
\hline Walthall & 0.0168 & $08.7 \%$ & 0.0001 & $00.1 \%$
\end{tabular}

Table 8: Absolute and relative RMSE and Bias between airborne and field albedo estimates for the four kernel-driven models and set of coefficients $n^{\mathrm{O}} 4$. 


\begin{tabular}{c||cc|cc}
$\begin{array}{c}\text { BRDF Model } \\
\text { \& Coefficient set }\end{array}$ & a & $\mathrm{b}$ & ARMSE $_{U}$ & RRMSE $_{U}$ \\
\hline \hline Walthall \& set $\mathrm{n}^{\mathrm{0}} 1$ & 0.9339 & 0.0483 & 0.0214 & $11.0 \%$ \\
\hline Walthall \& set $\mathrm{n}^{\mathrm{o}} 2$ & 0.8171 & 0.0527 & 0.0215 & $11.0 \%$ \\
\hline Walthall \& set $\mathrm{n}^{\mathrm{o}} 3$ & 0.8791 & 0.0416 & 0.0174 & $09.0 \%$ \\
\hline Walthall \& set $\mathrm{n}^{\mathrm{o}} 4$ & 0.7701 & 0.0443 & 0.0149 & $07.7 \%$
\end{tabular}

Table 9: Coefficients of the linear regression between field and airborne estimates of the albedo (a: slope, b: offset), and absolute/relative RMSE between PolDER estimates and the linear regression $\left(\mathrm{A} / \mathrm{RRMSE}_{U}\right)$. 